\title{
UM MÉTODO SIMPLES E INTUITIVO PARA DETERMINAR A EXCENTRICIDADE DA ÓRBITA DA TERRA ${ }^{+*}$
}

\author{
Guilherme de Almeida \\ Colégio Militar (atualmente professor aposentado) \\ Associação Portuguesa de Astrônomos Amadores (APAA) \\ Lisboa - Portugal
}

\begin{abstract}
Resumo
É sabido dos livros de texto que as órbitas dos planetas são elipses. Assim sendo, a Terra não escapa a esse fato. Será possível, com meios muito simples, tanto em equipamento como do ponto de vista matemático, determinar a excentricidade da órbita do nosso planeta em torno do Sol? É esse o objetivo deste artigo: Poder satisfazer a curiosidade de alguns leitores, que queiram fazer as medições necessárias e comparar os seus próprios resultados com os que se veem nos livros; e, ainda, servir de base a um programa de trabalho em uma escola secundária, para alunos de um grupo escolar ou clube científico de Astronomia. O fato de se poder fazer de dia, em duas ocasiões do ano escolar, é uma circunstância favorável adicional.
\end{abstract}

Palavras-chave: Órbita da Terra. Diâmetro aparente. Apogeu. Perigeu. Unidade Astronômica. Eixo maior e eixo menor de uma elipse. Focos de uma elipse. Excentricidade de uma elipse. Órbitas dos planetas. Órbitas dos cometas.

\footnotetext{
A simple and intuitive method to determinate the excentricity of Earth's orbit around the Sun

* Recebido: junho de 2012.

Aceito: outubro de 2012.
}

Cad. Bras. Ens. Fís., v. 30, n. 1: p. 165-176, abr. 2013. 


\begin{abstract}
It is known from textbooks that the orbit $f$ the planets are ellipses. Thus, the Earth does not escape this fact. Is it possible, with very simple means, both in equipment as the mathematical point of view, determine the eccentricity of the orbit of our planet around the Sun? That is the purpose of this article. It can satisfy some reader's curiosity, who want to make the necessary measurements and compare their own results with those that are seen in books, it can still form the basis of a work program in a High School, to students of a School Group or of an Astronomy Scientific Club. The fact that it can be done during the day, on two occasions of the school year, is an additional favorable circumstance.
\end{abstract}

Keywords: Orbit of the Earth. Apparent diameter. Apogee. Perigee. Astronomical unit. Major and minor axes of an elipse. Focus of an elipse. Eccentricity of an elipse. Orbits of planets. Orbits of comets.

\title{
I. O fundamento e a metodologia
}

Tal como afirma a $1 .^{\text {a }}$ lei de Kepler (publicada em 1609), a órbita que a Terra descreve em torno do Sol é uma elipse, situando-se o Sol em um dos focos dessa elipse (ver nota ${ }^{1}$ ). Nas figuras feitas, muitas vezes, exagera-se incrivelmente a forma da órbita do nosso planeta. Há representações que mostram essa órbita como uma circunferência (Fig. 1), e outras insistem em uma elipse muito excêntrica (Fig. 2).

Como a órbita da Terra tem a forma de uma elipse (Fig. 2), o nosso planeta, ao descrevê-la, passa por uma posição que é a mais afastada possível do Sol (o afélio), que ocorre por volta de 4 de julho de cada ano, e por uma outra posição (denominada periélio), na qual está à distância mínima da nossa estrela (próximo de 4 de janeiro de cada ano).

\footnotetext{
1 O objetivo deste artigo é a determinação experimental da excentricidade da órbita da Terra e não a explanação das leis de Kepler. No entanto, os leitores podem obter informação explicativa sobre essas leis na obra de Ferreira e Almeida ${ }^{[1]}$, referida no final deste artigo.
} 


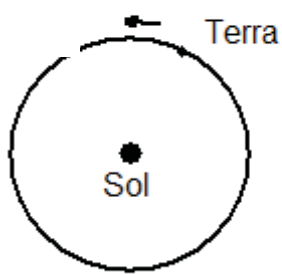

Fig. 1

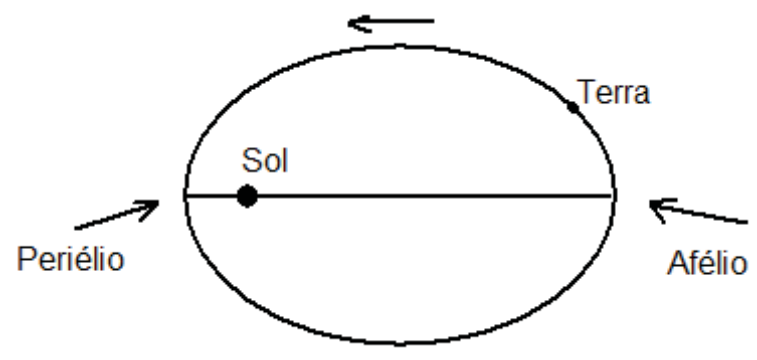

Fig. 2

\section{I.1 Discutindo a forma da órbita da Terra com base na evidência experimen- tal}

Como é, de fato a órbita da Terra? Mais parecida com a da Fig. 1 ou com a da Fig. 2? Se fosse como a da Fig. 1, veríamos o Sol sempre com o mesmo diâmetro aparente (Fig. 3) ao longo de todo o ano. Se fosse o caso da Fig. 2, deveríamos ver o Sol aparentemente muito menor quando a Terra passa no afélio, e bastante maior no periélio.

\section{Precaução essencial e experiência do observador}

Não se deve olhar para o Sol sem proteção visual apropriada. No caso de observações a olho nu, que não sejam muito prolongadas (duração inferior a cerca de cinco segundos), serve muito bem o filtro de proteção utilizado nas soldaduras por arco elétrico, com grau de opacidade 14, à venda nas lojas de ferragens a um preço muito acessível (pode-se comprar só o filtro de vidro ou dois filtros, um para cada olho, já montados em óculos apropriados, o que permite ter as mãos livres). Desaconselham-se todos os "filtros de improviso", como vidros fumados, películas fotográficas, óculos escuros, etc., que são extremamente perigosos por não permitirem a necessária proteção e porque os danos produzidos na retina são indolores e irreversíveis. Para mais informações, consulte-se a obra de Almeida ${ }^{[2]}$.

Sabe que pouca diferença se nota: à primeira impressão, o Sol parece mostrar-nos o mesmo diâmetro aparente durante todo o ano, o que significa que a órbita da Terra deve parecer-se mais com a Fig. 1 do que com a Fig. 2. Se fosse como na Fig. 2, o Sol pareceria cinco vezes maior no periélio do que no afélio (compare as distâncias), do mesmo modo que um automóvel, visto a $100 \mathrm{~m}$ de nós 
parece cinco vezes maior que a $500 \mathrm{~m}$. Por isso, a desigualdade do tamanho aparente do Sol ao longo do ano é um indicador da excentricidade da órbita da Terra.

\section{I.2 Determinando a excentricidade de órbita da Terra a partir da variação anual do diâmetro aparente do Sol}

Como o diâmetro aparente do Sol é pequeno (Fig. 3), pois mede cerca de $0,5^{\circ}$, podemos dizer que esse diâmetro aparente é inversamente proporcional à distância a que estamos dele. Isso quer dizer que, se a distância da Terra ao Sol duplicasse o diâmetro aparente $(d)$ reduziria à metade; se a distância triplicasse, passaria a ser um terço, etc. Para facilitar as indicações que daremos seguidamente, representaremos a distância da Terra ao Sol, no periélio, por $r_{\mathrm{p}}$ ("p" de "periélio") e por $r_{\mathrm{a}}$ no afélio. A Fig. 4 mostra alguns parâmetros geométricos de uma elipse. Desta figura, concluímos, facilmente, que $r_{\mathrm{p}}=a-c$ e que $r_{\mathrm{a}}=a+c$.

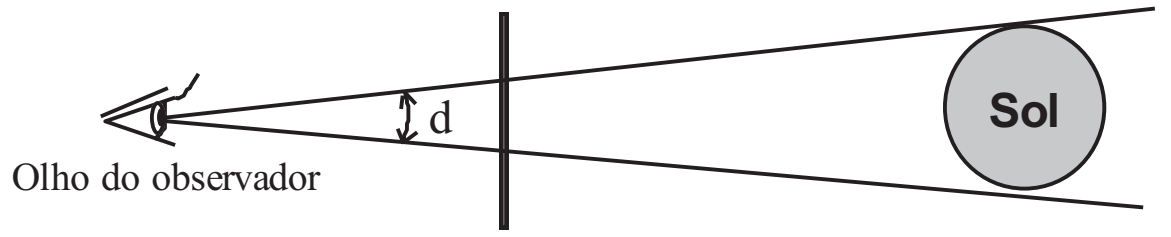

Filtro

Fig. 3 - O diâmetro aparente do Sol é o ângulo indicado pela letra d. As dimensões aparentes são sempre angulares. Essa noção é aplicável a outras situações (por exemplo, o diâmetro aparente da Lua, ou a altura aparente de um prédio visto a uma certa distância do observador.) Para maior clareza, a figura não foi desenhada em escala.

Como o diâmetro aparente do Sol, visto da Terra, é inversamente proporcional à distância a que dele nos encontramos, podemos escrever

$$
\frac{d_{p}}{d_{a}}=\frac{r_{a}}{r_{p}}, \text { ou seja, } \frac{d_{p}}{d_{a}}=\frac{a+c}{a-c}
$$

Dá-se o nome de excentricidade de uma elipse ao parâmetro $e=c / a$ (Fig. 4), onde $d_{\mathrm{a}}$ é o diâmetro aparente do Sol no afélio, e $d_{\mathrm{p}}$ no periélio. Porém, como $c=e a$ (visto que $e=c / a$ ), pode-se também escrever

$$
\frac{d_{p}}{d_{a}}=\frac{a+e a}{a-e a}=\frac{a(1+e)}{a(1-e)}, \text { que é equivalente a } \frac{d_{p}}{d_{a}}=\frac{1+e}{1-e},
$$


Dessa última expressão, concluímos que

$$
d_{p}-d_{a}=e\left(d_{p}+d_{a}\right) \text { e, consequentemente, } e=\frac{d_{p}-d_{a}}{d_{p}+d_{a}} .
$$

As medições atuais permitem concluir que o diâmetro aparente do Sol varia, ao longo do ano, entre 32,58' (no periélio) e 31,51' (no afélio), onde ( ' ), é, como se sabe, o símbolo do minuto angular. Baseando-nos nestes valores, concluímos que

$\frac{32,58-31,51}{32,58+31,51}=e$, de onde obtemos, feitas as contas, $e=0,01669$.

É precisamente essa, segundo as melhores determinações atuais, a excentricidade da órbita do nosso planeta em torno do Sol, valor frequentemente arredondado para 0,0167 . Ficamos satisfeitos? Nem por isso, pois os valores dos diâmetros aparentes do Sol não eram nossos, e um amador não pode aspirar a tal exatidão na medição do diâmetro aparente do Sol. Vamos, portanto, usar valores medidos por nós, com o nosso material e nas nossas condições, nunca excelentes mas que nos poderão proporcionar um outro nível de satisfação.

Projetamos a imagem do Sol, em um ecrã de papel, com uma luneta diafragmada ou com um telescópio criteriosamente diafragmado. Não há nada a recear se diafragmar a $f / 40$ (diâmetro do diafragma $=1 / 40$ da distância focal da objetiva). Nas várias medições, utilize o mesmo telescópio, com a mesma ocular para o projeto (de preferência, de distância focal entre $20 \mathrm{~mm}$ e $30 \mathrm{~mm}$ ). É essencial que se mantenha constante, em todas as medições, a distância desde a ocular até ao ecrã de projeção (use uma vara de madeira como bitola). Nessas condições, o diâmetro da imagem do Sol, projetada no ecrã, é diretamente proporcional ao diâmetro angular da nossa estrela.

O ecrã deve estar fixo, ao solo (com tripé), ou ao telescópio. A imagem deverá estar bem focada. Pegue uma régua graduada e, encostando-a ao ecrã, meça o diâmetro da imagem do Sol a 4 de julho e depois a 4 de janeiro. Ser-lhe-á difícil medir o diâmetro com erro inferior a $1 \mathrm{~mm}$, e as ondulações do limbo solar não facilitam. Também será difícil saber que estamos mesmo a medir o diâmetro, pois o bordo da régua pode estar passando ligeiramente ao lado do centro da imagem do disco solar e não percebermos isso. 


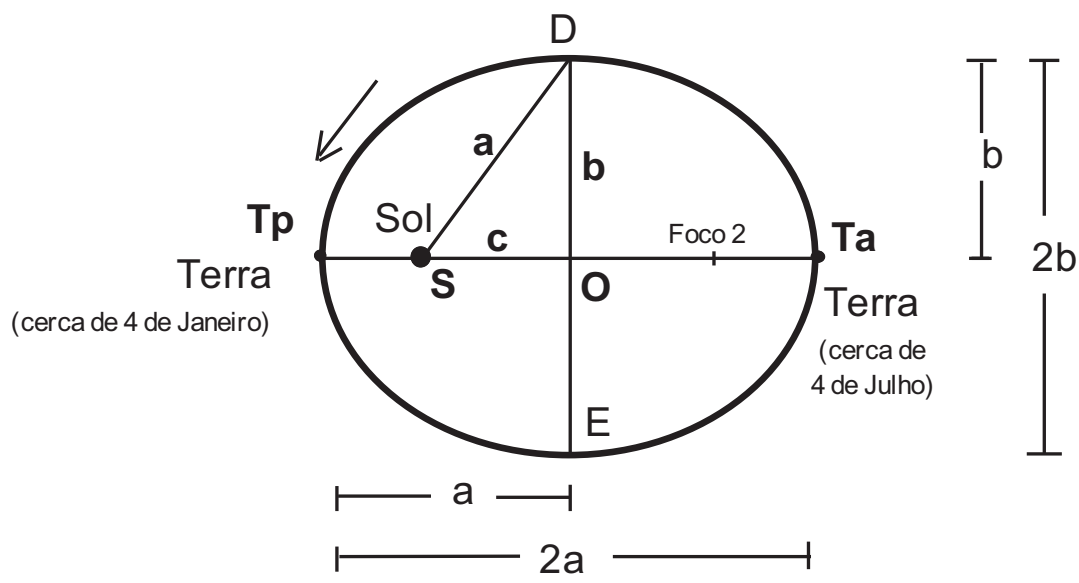

Fig. 4 - As indicações Tp e Ta representam as posições da Terra no periélio e no afélio, respectivamente.

Pelas razões apontadas, convém fazer várias medições (pelo menos 4), tirando e voltando a colocar a régua, em cada uma das medições, calculando depois, em cada data, a média dos valores medidos. Por exemplo, admitamos que obtivemos 120,0 mm como diâmetro médio da imagem a 4 de julho, valor que representaremos por $D_{\mathrm{a}}$ (diâmetro da imagem no afélio), e 124,5 $\mathrm{mm}$ no periélio, a 4 de janeiro $\left(D_{\mathrm{p}}\right)$. Podemos continuar a utilizar a expressão anterior, que relaciona a excentricidade da órbita da Terra com os diâmetros aparentes do Sol no afélio e no periélio

$$
e=\frac{d_{p}-d_{a}}{d_{p}+d_{a}}, \quad \text { escrevendo agora } \quad e=\frac{D_{p}-D_{a}}{D_{p}+D_{a}},
$$

visto que, nas condições em que trabalhamos, o diâmetro aparente da imagem projetada no ecrã é diretamente proporcional ao diâmetro aparente do Sol. Introduzindo nesta última expressão os nossos valores de $D_{\mathrm{p}}$ e $D_{\mathrm{a}}$, obtemos

$$
e=\frac{124,5-120,0}{124,5+120,0}=0,0184
$$

que é um resultado bastante satisfatório para um trabalho feito com meios tão simples. Repare-se que uma diferença de 0,0184 - 0,0167 =0,0017, o que, em 0,0167, dá um erro relativo de cerca de $10 \%$, mas é possível obter resultados bem melhores. Na série II deste artigo, serão mostrados os resultados práticos. 


\section{I.3 Elipse, ou quase circunferência?}

Embora o observador esteja à superfície da Terra, e não no seu centro, podemos desprezar as dimensões do nosso planeta face às dimensões da sua órbita. De fato, a órbita da Terra é uma elipse, mas a sua excentricidade é tão pequena que mais parece uma circunferência. Façamos um desenho cuidadoso, e grande, à escala, com o eixo maior (a distância $2 a$ na Fig. 4) a valer precisamente $1000,0 \mathrm{~mm}$. Nessas condições, na mesma escala, quanto mediria o eixo menor (distância $2 b$ na mesma figura)? O cálculo é simples. Da Fig. 4, conclui-se que $a^{2}=b^{2}+c^{2}$. Vimos, também, que $e=c / a$ ). Portanto,

$$
\begin{gathered}
\frac{a^{2}}{b^{2}}=\frac{a^{2}}{a^{2}-c^{2}}=\frac{a^{2}}{a^{2}-a^{2} e^{2}}, \text { ou seja, } \\
\frac{a^{2}}{b^{2}}=\frac{a^{2}}{a^{2}\left(1-e^{2}\right)}=\frac{1}{1-e^{2}},
\end{gathered}
$$

o que nos permite concluir que

$$
\frac{a}{b}=\sqrt{\frac{1}{1-e^{2}}}, \text { e, portanto, } \frac{a}{b}=\sqrt{\frac{1}{1-e^{2}}} .
$$

Introduzindo nessa última expressão o valor da excentricidade da órbita da Terra $(e=0,0167)$ e de $2 a$ (que queremos desenhar com 1000,0 mm), concluímos que o eixo menor mediria $999,86 \mathrm{~mm}$ (portanto, a diferença $2 a-2 b$ é apenas de $0,14 \mathrm{~mm}$ ). Distingue-se de uma circunferência?

E o Sol, no desenho, ficaria a que distância do centro da elipse?

Chega-se rapidamente a esse valor, como vamos mostrar. Essa distância ( $c$ na Fig. 4) é dada pela relação $c=e a$ (que vimos anteriormente). Por isso, no desenho, $c=0,0167 \times 500 \mathrm{~mm}=8,35 \mathrm{~mm}$. Em um desenho menor, as diferenças seriam ainda menos detectáveis. No "tamanho natural", a órbita da Terra tem

$$
\begin{aligned}
& a=149,598 \text { milhões de quilômetros } \\
& b=149,577 \text { milhões de quilômetros; } \\
& c=2,498 \text { milhões de quilômetros; } \\
& \mathrm{e}=0,0167 \text { (não depende da escala, como é óbvio). }
\end{aligned}
$$

Uma elipse com excentricidade igual a zero é uma circunferência. Quanto maior for a excentricidade de uma elipse, mais alongada esta será. No limite, a excentricidade de uma elipse aproxima-se de 1, sem atingir esse valor. A órbita de Plutão, por exemplo, tem excentricidade 0,25 ; no caso de Vênus, é apenas de 0,007. A excentricidade da órbita da Lua em torno da Terra é 0,055 , porém, a ex- 
centricidade das órbitas dos cometas é bastante superior (cerca de 0,97 , no caso do cometa Halley). Sabidas as distâncias ao Sol, em média, no afélio e no periélio, para obter a excentricidade da órbita respectiva, basta fazer

$$
\frac{r_{a}}{r_{p}}=\frac{1+e}{1-e} \mathrm{e}, \text { portanto, } e=\frac{r_{a}-r_{p}}{r_{p}+r_{p}}
$$

No caso do cometa Halley, $r_{\mathrm{p}}$ e $r_{\mathrm{a}}$ medem aproximadamente 0,6 u.a. e 35 u.a., respectivamente. A indicação "u.a." designa a unidade astronômica, distância usada como padrão dentro do Sistema Solar e equivalente aproximadamente à distância média da Terra ao Sol (149,6 milhões de quilômetros).

Os jardineiros aprenderam há muito a técnica (empírica) para desenhar elipses (Fig. 5): espetam duas estacas no solo, à distância $2 c$ uma da outra; atam um pedaço de corda, de uma estaca até à outra, ficando o comprimento $2 a$ de fio livre entre as estacas; colocam uma vara afiada, que vai marcar o solo, de modo a esticar o fio, e traçam a elipse, mantendo o fio sempre esticado.

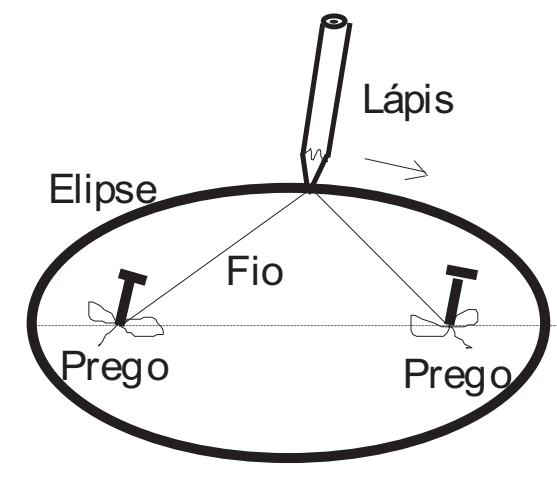

Fig. 5 - O traçado de uma elipse pelo método do jardineiro.

Como se conclui da Fig. 5, é fácil desenhar uma elipse com dois pregos e um fio, em uma tábua, usando um lápis. Seguindo as indicações dadas, a elipse pode ser traçada de acordo com os parâmetros pretendidos. 


\section{Os procedimentos e os resultados}

Na seção anterior, vimos o fundamento do processo experimental para a determinação da excentricidade da órbita descrita pela Terra em torno do Sol. Seguindo as indicações já dadas anteriormente (cuja consulta se recomenda), apresentam-se, agora, os procedimentos práticos e os resultados obtidos, aos quais se juntam algumas indicações úteis.

\section{II.1 Equipamento utilizado}

Para essas medições, foi utilizado um telescópio refletor de Newton, com $110 \mathrm{~mm}$ de abertura e $805 \mathrm{~mm}$ de distância focal $(f / 7,3)$. Para proteger a ocular e o secundário de aquecimentos excessivos, o telescópio foi diafragmado com um orifício circular, descentrado, com $35 \mathrm{~mm}$ de diâmetro $(f / 23)$. A montagem equatorial tinha movimentos lentos manuais, mas não estava motorizada, o que dificultou o trabalho (embora estivesse orientada). O ecrã de projeção estava solidário com a extremidade do eixo de declinação, movendo-se, consequentemente, com o tubo óptico. Sobre o ecrã, assentou-se um pedaço de papel, prendendo-o com clipes. Os traços foram marcados com uma lapiseira de ponta fina.

Para a projeção, foi utilizada uma ocular de Plössl de $25 \mathrm{~mm}$ de distância focal. A distância entre a ocular e o ecrã de projeção foi de $360 \mathrm{~mm}$, padronizada por uma bitola de madeira de modo a garantir a repetição dessa distância nas medições feitas no periélio e no afélio. A título de indicação, a distância focal equivalente do conjunto, embora não seja necessária a este trabalho, foi de 11,05 m.

\section{II.2 Metodologia de trabalho}

Centrada a imagem do Sol no ecrã de projeção, regulou-se a distância entre esta e a ocular, e aprimorou-se a focagem (com a bitola de madeira confirmouse que a distância era de $360 \mathrm{~mm}$ ). O método baseou-se na marcação de pares de traços diametralmente opostos entre si e tangentes ao disco solar. Marcaram-se, assim, os traços 1 e 1', 2 e 2', 3 e 3', 4 e 4', etc. Os traços de cada par são paralelos entre si e a distância entre eles é o diâmetro da imagem solar. 


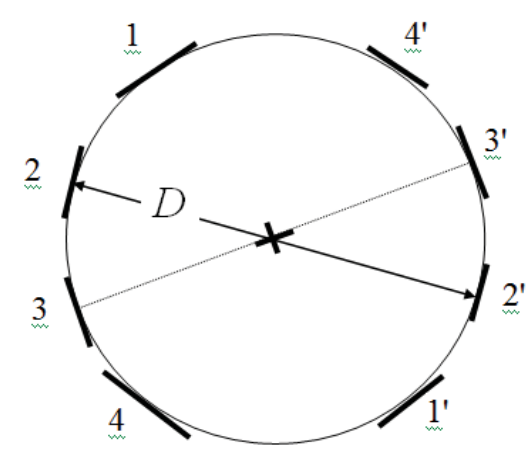

Fig. 6

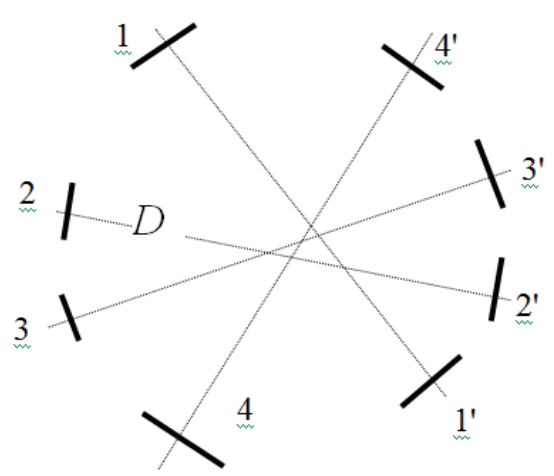

Fig. 7

Fizemos-se cinco medições em cada ocasião (cinco no periélio e cinco no afélio). Como é óbvio, utilizamos um papel para todas as marcações referentes ao periélio e outro para as que se referem ao afélio. Em cada uma dessas datas, foi rejeitada a pior medida (a que apresentava maior discrepância em relação às restantes e correspondia a uma medição de inferior qualidade). Trabalhamos, assim, com quatro medidas de cada vez. Retiramos seguidamente o papel dos clipes e medimos, com uma régua graduada, a distância entre cada par de traços. Essa medição é rigorosa até ao milímetro. Por estimativa, avaliamos décimos de milímetro. Nessas medições, devemos olhar perpendicularmente ao papel, para minimizar erros de leitura.

As primeiras medições foram feitas em 4 de janeiro de 1999, próximo da data do periélio (que ocorreu nesse ano, em 3 de janeiro; um ou dois dias a mais ou a menos fazem pouca diferença). As medições no afélio foram feitas em 4 de julho de 1999 (véspera da data do afélio), em um dia com algumas nuvens, por isso aproveitamos os pequenos intervalos de tempo em que o Sol ficava descoberto.

As medições podem fazer-se como se vê na Fig. 6. No entanto, devido principalmente à rotação da Terra, nas montagens não motorizadas, o Sol "foge" entre a marcação de um traço e a marcação do traço diametralmente oposto, o que obriga a reposicioná-lo constantemente, com os movimentos lentos da montagem. Pode-se, também, ver antecipadamente em que sentido é que a imagem do Sol se está a "deslocar", e marcar um traço antes de o limbo solar chegar lá. Aguarda-se, já com o lápis à espera, do lado oposto. Quando o limbo solar passa no primeiro traço, marca-se rapidamente o traço do lado diametralmente oposto. Note-se que o 
que é necessário é que cada par de traços toque dois pontos diametralmente opostos do disco solar. Cada diâmetro deve ser marcado com cuidado. No entanto, não é necessário que os sucessivos diâmetros se cruzem rigorosamente no mesmo ponto (Fig. 7). Por outras palavras, pequenos desvios entre a posição do centro da imagem do Sol quando se marca um par de traços e quando se marca o outro par não são importantes, desde que cada par de traços diste entre si de uma medida correspondente ao diâmetro da imagem solar. As Fig. 6 e 7 são representações esquemáticas, meramente descritivas do procedimento; não são réplicas dos traçados feitos e medidos.

\section{Medidas do diâmetro da imagem do Sol, com a Terra no periélio}

As medidas obtidas para o diâmetro da imagem projetada do Sol, no periélio, foram as seguintes: $104,5 \mathrm{~mm}, 105,0 \mathrm{~mm}, 105,2 \mathrm{~mm}, 105,4 \mathrm{~mm}$. A média aritmética dos valores anteriores foi $D_{\mathrm{p}}=105,0 \mathrm{~mm}$.

\section{Medidas do diâmetro da imagem do Sol, com a Terra no afélio}

As medidas obtidas para o diâmetro da imagem projetada do Sol, no afélio, foram as seguintes: $100,6 \mathrm{~mm}, 101,0 \mathrm{~mm}, 102,0 \mathrm{~mm}, 101,5 \mathrm{~mm}$. A média aritmética dos valores anteriores foi $D_{\mathrm{a}}=101,3 \mathrm{~mm}$. Os cálculos, de acordo com o que foi indicado na primeira parte, ficam

$$
e=\frac{D_{p}-D_{a}}{D_{p}+D_{a}}=\frac{105,0-101,3}{105,0+101,3}=0,0179 .
$$

Obtivemos, assim, o nosso valor para a excentricidade da órbita da Terra $e=0,0179$. Será esse um bom valor? O valor atualmente aceito, segundo as melhores determinações, é $e_{\mathrm{T}}=0,0167$. Utilizamos, aqui, o índice " $T$ " para indicar que é $o$ valor que aparece normalmente em Tabelas, distinguindo-o do que resultou das minhas medições. O erro relativo é, consequentemente,

$$
\frac{\Delta e}{\mathrm{e}_{\mathrm{T}}}=\frac{e-\mathrm{e}_{\mathrm{T}}}{\mathrm{e}_{\mathrm{T}}}=\frac{0,0179-0,0167}{0,0167}=0,0718 \approx 7,2 \%
$$

Repare-se que, apesar de todo o cuidado, foi deixada margem para os leitores fazerem melhor. Uma montagem motorizada (e orientada) deixaria o Sol a deslocar-se muito lentamente para leste (apenas devido à translação da Terra), o que seria desprezível durante a curta duração dessas medições (dois períodos de 10 minutos, para minimizar o aquecimento das peças ópticas). Assim, a imagem do Sol ficaria praticamente imóvel no ecrã, e a marcação dos traços seria muito mais 
cômoda e rigorosa. Nessas condições, seria possível obter um valor ainda mais próximo de 0,0167 .

Procuramos mostrar que é possível chegar a resultados interessantes, com erro relativamente baixo, utilizando meios e procedimentos simples. Não se trata, aqui, de competir com os observatórios. Tendo isso em consideração, o resultado alcançado pode ser considerado "bom". Os leitores farão certamente ainda melhor.

\section{Uma nota final}

Rigorosamente, devemos ter em conta que o observador não está no centro de massa do sistema Terra-Lua, mas sim à superfície da Terra. E "quem" descreve a elipse em torno do Sol (com a excentricidade 0,0167) é esse centro de massa (CM). A distância Sol-observador difere, em poucos milhares de quilômetros, da distância Sol-CM, e essa diferença depende de fatores ligados ao momento e ao local de observação. No entanto, a repercussão dessa diferença no valor da excentricidade obtida é muito pequena e, para os nossos propósitos, podemos desprezá-la. Por isso, os nossos resultados podem ser melhores, mas serão ligeiramente diferentes do valor tabelado (que já é corrigido da diferença atrás referida).

\section{Referências}

${ }^{[1]}$ FERREIRA, M.; ALMEIDA, G. de Introdução à Astronomia e às Observações Astronômicas. 7. ed. Lisboa: Plátano Editora, 2004. Referência e sinopse disponível em:

$<$ http://www.platanoeditora.pt/index.php?q=C/BOOKSSHOW/16>.

[2] ALMEIDA, G. de Telescópios. Lisboa: Plátano Editora, 2004. Referência e sinopse disponível em:

$<$ http://www.platanoeditora.pt/index.php?q=C/BOOKSSHOW/15>. 